\title{
Discover your Child: Is He/ She Abused by You Inside the House?
}

\author{
Intisar Turki ALdarabah, Reham Almohtadi \& Mohammad Abo Alrub \\ School of Education, Al-Hussein Bin Talal University, P.O. Box (20), Ma'an, Jordan \\ E-mail: Entesusm@yahoo.com
}

Received: June 14, 2015 Accepted: August 18, 2015 Published: August 18, 2015

doi:10.5296/jse.v5i3.6378

URL: http://dx.doi.org/10.5296/jse.v5i3.6378

\begin{abstract}
This research seeks to reveal to the parents if they are abusing their children without knowledge inside the house. In order to answer the study questions, an instrument was developed to measure the abused behavior extent of including the items of abused. The instrument consisted of 50 items that involved five subscales. The instrument's validity was tested through introducing it to specialists' reviewers. Also the stability analysis was tested by re-analysis. The statistic data and frequencies were used to investigate the availability of the abused behavior. The study results showed that the mothers do not have the sufficient knowledge about the concept children abuse, inside the house, since the responses to all of the dimensions were below the medium, and some of the fathers and mothers abuse their children thinking that this is one of disciplines to make them acquire the desired behavior, and preventing them from the abnormal behavior.
\end{abstract}

Keywords: Abused, Mothers, Abused behavior, Inside home 


\section{Introduction}

Child abuse concepts became one of the important issues that receive special interest from the different institutions and parties, starting from the family, the psychological education, educational counselors and the social \& religious specialists (Al-Jabali, 2004). The search in children abuse problem requires knowing the participating parties in this phenomenon, (Wolf and Wilson, 1990). The child's to decode the symbols and the non-oral messages sends denouncing the ways in which he is treating, either opposing or protesting (Al-darabah, 2011).

Children abuse is not considered a new phenomenon to the societies, rather presented long time ago. Currently child abuse considers one of the phenomenon that has been disseminated widely and rapidly day after day (Journal of childhood and Development, 2001). Child abuse may take multiple forms, like physical punishment targets the child's body like hitting, and causing harm, and might be psychological that threatens the child's psychological security, or moral that humiliates the children's dignity and humanity, and it could be aggression against his security, rights, and requirements (Mansi et al, 2000).

One of the elements that causes child abuse is the parents ignorance, by holding the wrong beliefs about their role as parents, how to educate their children (Journal of Arabic Childhood, 2000). Also, ignorance of the child's rights that are due for fulfillment by the parents, such as parental law required skills to interact with the children, such as talking to them $\&$ touching them geniality.

Those parents' skills are characterized by violence and passiveness; on the other hand the over-protection or the severe pressure may be one of the reasons that make the father haphazardly in his behavior (Abu- Al- Sondos, 2004). Also, the younger fathers suffer from the difficulty in meeting their children's needs, and because they are young they lack more of experience needed to deal with their children (Heidi, 2004). In addition, the mother going out for work for long hours during the day, depriving the child from the compassion and tenderness translates in to wrong treatment in upbringing (Ratroot, 2001, Wallace, 2005). Ismael (2001) sees that the parents and the custodians use of different methods in upbringing and care, that range from love, care to ignorance or severity and punishment, that in many cases turn to severe physical punishment like hitting or psychological punishment like humiliating and scorning (Margolin, 1998).

The behaviors practiced by the parents or the child's custodians or other individuals from outside the family range to the child classifies under the little child abuse. Salama (1991) indicates that the abuse fall at positive side, love and acceptance, and the negative side the killing, and at the middle area the parents abuse or the parents violence against the child. AlHadeedi and Jahshan (2004) see that what is agreed upon is that the parents on the child's custodians have the duty to direct, upbringing and avoiding the child any life risks, while others agreed upon that the child's over-protection may result in child abuse; ad here evolves the defect in the equation between abuse and discipline. 
Finally, Jordan considers one of the countries that actively seek to raise the level of the general awareness about this problem, especially the concepts child abuse inside the family still one of the concepts that is un-clear for a large segment of people in the Jordanian society, since the abuse is taken as one kind of children discipline. Revealing the information that the parents poses about the violence problem, children neglect and abuse, the extent of their awareness about these issues. The scope of this research limits the meaning, because child abuse practices start from the family, and the child's treatment behaviors start by cases of harm that fall within the strong and intimate relations between the child and his family members.

\section{Problem of the Study}

Identifying children abuse till the present has not been determined accurately and precisely. It is noted that there are those who focus on the upbringing and disciplining culture, and they do not know the traits of this process and un-aware of its appropriate scientific methods of this process (Al-Sayeg, 2001).

In the Arab world, the interest in this phenomenon has started very late, and even when this interest has started it came very limited. The number of the scientific researches that has addressed this topic was very small in Jordan compared to the number of the researches in the foreign countries. Children abuse concept considers completely un-clear to a large social segment in the Jordanian society, taking in to account that the abuse takes forms of the disciplining, or the children's education. Because of the importance of the children abuse problem, and the negative effects that it leaves on the child's physical and psychological growth, and embedding his normal development and his normal growth paths, the researchers in the childhood field rapidly conducted many of the studies and researches, preparing the measurements, setting the treatment and the precautionary methods for it in order to overcome the negative effects linked to.

Also, the studies points to the absence of agreement and the mix in the concepts related to the children abuse generally, because such behaviors cannot be considered as severe by most of the people they are very common acts (Straus, $1991 \& 1999)$ studies pointed that (90\%) of parents use some forms of violence and physical abuse with their children, and the percentage of the children who were subject to the physical punishment ranged from (93\% - 95\%). From this point came the problem of the current study in determine the extent of parents perception care providers to the children on scanning, and the parents identification and gaining the awareness about the child abuse methods inside the house.

\section{Significance of the Study}

The importance of this current study comes from diagnosing parents and the care providers to the child if they abuse the childe without awareness, and the extent of the information they poses to know the child abuse phenomenon. Many of the parents perform acts like detention for long period thinking that this is not a form of child abuse. We see many of daily acts from the parents toward their children inter in the topic child abuse, either in the implication or in the causing factors or the resulted outputs. So, we find that till now, addressing this topic 
ambiguous and contradiction, starting from identifying this phenomenon, ending with the ways to treat it.

As a result, since the societies have different culture, it is difficult to place a comprehensive definition to the child abuse, because what is considers appropriate behavior in dealing with the child in one society might not considers appropriate behavior in another society, but there is the agreement that hitting the child to a degree that causes physical and psychological harm to him even on the long term is rejected. The importance of this study also came from children's abuse as a chain repeats generation after generation, because the child who has experienced the abuse trauma repeats the methods in the youth period, even in its ugliest forms, so the abuse transforms to the next generation. The only way to stop this chain is the work with the parents or the custodians to rise the culture ceiling and self-development and the educational development to rise the relations culture especially with the children.

Also, the importance of this present study comes from the researcher's experience in dealing with the children's mothers through the training courses, since it became clear from their experiments in upbringing the children the mothers fall in the mistake about some of the methods, since the mother considers shouting severely to the child if he makes mistakes or punishing him for every simple mistake is one of the child's disciplinary methods to correct his behaviors by an accepted way by the others and the society, but she does not know that she is really is falling in a new problem which is child abuse without knowledge or awareness about that. The importance of this study becomes prominent from being also a response to the scares studies and the research efforts in the field parents perceptions and perspectives about the abuse problem in treating the children in the Jordanian society, especially that most of the previous studies have addressed the abuse modes and the extent of their frequency, and the different factors that lead to children abuse.

\section{The Questions of the Study}

This study seeks to reveal to the parents if they are abusing their children without knowledge, this becomes clear by asking the following question

-What is the extent of the mother's knowledge about the behaviors related to the child abuse inside the house?

\section{Literature Review}

Abu Jaber el al., (2008) conducted a study that aimed to know the type and the level of the perception, awareness and the information related to the children's neglect, physical and sexual abuse to the fathers and mothers living in Amman City. The research sample consisted of parents from the age category (25-65) years.

The study reached the spread awareness about the dangerous problem the children's neglect and abuse, its escalation and the resulted physiological effects.

Rbaihat (1988) has reached in his study about the size and the forms of children abuse in Jordan, that the percentage of the children's cases under the age 15 years old who were subject to the physical harm represented nearly (29.45\%) from the total victims of the simple 
physical harm, and the age category that was more subject to sexual harm was between (7-12) years old, with the percentage $(63.5 \%)$ in addition to the increasing cases of children neglect by the family individuals related to accidents traumas, the percentage reached $(87.8 \%)$.

Also, Khalqi (1990) has conducted a study about the Jordanian child's physical and sexual abuse and some of the demographic variables related to the abusing family. The study sample included (102) case of the registered cases in the general security as physical and sexual abuse. The most prominent result that the study reached the percentage of the physical abuse against the males was higher than the percentage for the females, while the females are more subject to the sexual abuse than the males. Also, showed the increasing physical and sexual abuses against children within the lower economic level category, and the highest percentage of the abuse perpetrators belong to low educational level.

Al-Tawrawneh (1999) has conducted a study that aimed at studying the type of parents abuse of their sons and its relation with some of the demographic variable (education and income) and the psychological (psychological stress) specific to the parents, using a stratified random sample consisted of (913) students, (455) males and (458) females from the tenth grade in Al-Karak Governorate. The results showed that the sample's individuals were subject to the forms of parents abuse at different degrees, the most frequent the psychological abuse, followed by the neglect abuse, finally the physical abuse, in addition the males were subject to the three forms of abuse more than the females (The physical, neglect and the psychological abuse).

Al-Ratroat (2001) has conducted a study about the abuse modes against children from their family members and its relation with some variables and social and economic characteristics of the children and the abusing individuals. The study included (981) case of the abuse cases registered in the social service office that links with the family protection unit in the general security in the year (1999), from these cases (199) negligence cases, (26) sexual abuse, and (256) physical abuse.

To know the opinions and the perception of the society individuals related to the sexual abuse against children, a research team from the university of Massachusetts has conducted a study in the year (2003) a survey study in which a random sample has been selected and consisted of (325) respondents, (50\%) females and (50\%) males, results showed that (40\%) of the study sample know little about sexual abuse, while (38\%) do not know the problem sufficiently, and $(57.1 \%)$ indicated that sexual abuse represents a dangerous problem in the society.

\section{The Study Procedures}

\subsection{Study Population and Sample}

Study population of the current study consists of all the mothers that the official records indicate they have sons and live in Ma'an City, the number is (100) mother (The Jordanian General statistics department, 2014), whose ages ranged from (25-60) years old. The study sample that represents Ma'an City was selected by following the random method, as a result, the study sample individuals number reached (100) mother, and the number of the responded mothers by filling all the data specific to the study questionnaire reached (79) mother. 


\subsection{Study Instruments}

A scale to reveal the child abuse by the mothers, and a questionnaire has been developed about concepts relating to the children abuse, (Al-Balbeesi, 1997. North Dakota state, 1999, Al-Tarawneh, 2001, data center -North Dakota state university, Massachusetts, 2003, street and market research, 1997).

A number of items were gathered from previously used scales, with some needed modifications to be consistent with the study goal

\subsection{Validity of the Scale}

a- Instrument's validity: to test the validity instrument it has been introduced to an arbitrating committee that consisted of a group of teaching staff members, their number was (11) teaching staff members from the educational sciences faculties in the university of Jordan, Al-Hashmeiah and Al-Balqa applied university.

They were asked to give their opinions about the relevance of the instrument's items to the concepts it has been set to measure, in addition to suggest what they see appropriate of new items and ideas.

$(80 \%)$ agreement and more on the item considered the indicator and the evidence to the item's validity. In the light of the arbitration committee result, some of the items were omitted and adjusted, adding other items to the present items. The questionnaire in its final form consisted of (50) items that covered all the methods practiced by the mothers in dealing with the children.

\section{Results}

To answer the research question whichis: What is the extent of the mother's knowledge about the behaviors related to the child abuse inside the house? Table (1) illustrates the mean and standard deviation frequencies. 
Table 1. Descriptive Statistics of Items on Group One

\begin{tabular}{|l|c|c|r|}
\hline \multicolumn{1}{|c|}{ Item } & $\mathrm{N}$ & \multicolumn{1}{|c|}{ Mean } & Std. Deviation \\
\hline $\begin{array}{l}\text { I make fun of him. } \\
\text { I don't forget doing the things specific to } \\
\text { him }\end{array}$ & 50 & 2.2400 & .87037 \\
I severely shout at him if he makes & 50 & 2.2800 & .60744 \\
mistakes & 50 & 2.3000 & .67763 \\
I talk to him with tenderness and & & & .58693 \\
compassion. & 50 & 2.3200 & .62073 \\
When he gets in trouble I make him feel & 50 & 2.3400 & .65807 \\
he is wrong. & 50 & 2.3400 & .65807 \\
I scold him when he makes a mistake. & 50 & 2.3800 & .69664 \\
I praise him in front of his friends. & 50 & 2.4000 & .67006 \\
I refuse listening to his complaint in order \\
not to spoil him.
\end{tabular}

The results of the descriptive analysis showed that "I make fun of him.", was at a lower level compared to the above ten items. It can be inferred that this item is the relative weaknesses at the mother, it exhibited very low level mean scoreswith $(\mathrm{M}=2.2400$, S.D. $=.87037)$. Thus, it can be concluded that this item of group one can still be unknown to the mothers. Meanwhile, the descriptive analysis showed that "I use harshness on him for his interest "Was at a highest level compared to the above ten items. 
Table 2. Descriptive Statistics of Group Two

\begin{tabular}{|c|c|c|c|}
\hline & & Mean & Std. Deviation \\
\hline I feel he is un-accepted from his friends. & 50 & 2.2200 & .76372 \\
\hline I like spending a lot of time with him & 50 & 2.2800 & .53605 \\
\hline I make him feel guilty if he misbehaves. & 50 & 2.3000 & .70711 \\
\hline $\begin{array}{l}\text { I punish him for every simple fault he } \\
\text { commits. }\end{array}$ & 50 & 2.3400 & .55733 \\
\hline I care about everything he does. & 50 & 2.4200 & .60911 \\
\hline I help him in anything he asks. & 50 & 2.4200 & .60911 \\
\hline I care about listening to his opinion. & 50 & 2.4400 & .67491 \\
\hline I embarrass him in front of his brothers. & 50 & 2.4600 & .70595 \\
\hline I care about knowing his friends. & 50 & 2.4800 & .64650 \\
\hline $\begin{array}{l}\text { Sometimes I'm forced to threatening and } \\
\text { scaring him }\end{array}$ & 50 & 2.4800 & .64650 \\
\hline
\end{tabular}

"I feel he is un-accepted from his friends", yielded the lowest mean score among all the items of group two with $(\mathrm{M}=2.2200$, S.D. =.76372). On the other hand, two items showed "I care about knowing his friends. " and "Sometimes I'm forced to threatening and scaring him", belonged to the highest level of the ten items. 
Table 3. Descriptive Statistics of the Group Three 2015, Vol. 5, No. 3

\begin{tabular}{|l|r|r|l|}
\hline & \multicolumn{3}{|c|}{ Mean } \\
\hline I leave him with the neighbors when I'm busy & 50 & 2.1800 & .80026 \\
I make him feel that his ideas and opinion are & 50 & 2.1800 & .71969 \\
acceptable. & & & \\
His idea about himself is low. & 50 & 2.2400 & .77090 \\
He tends to be isolated. & 50 & 2.3000 & .76265 \\
His moral spirit is always high. & 50 & 2.3800 & .69664 \\
He is able to make relations with the others. & 50 & 2.3800 & .63535 \\
I often deprive him from my compassion. & 50 & 2.4000 & .72843 \\
He fears the strangers. & 50 & 2.4000 & .67006 \\
I allow him to expresses his opinion without & 50 & 2.4400 & .70450 \\
discussing him. & & & \\
I require things from him by shouting nervously. & 50 & 2.4600 & .67643 \\
Valid N (listwise) & & & \\
\hline
\end{tabular}

In this section, the data obtained from the questionnaire related to group three exhibited that the "I leave him with the neighbors when I'm busy" was at lowest level(see table 3), with (M $=2.1800$, S.D. $=.80026$ ). 
Table 4. Descriptive Statistics of the Group Four

\begin{tabular}{|l|c|r|l|}
\hline & \multicolumn{2}{|c|}{} & \multicolumn{2}{|c|}{ Mean } & Std. Deviation \\
\cline { 3 - 4 } He steals from the house. & 50 & 2.1200 & .82413 \\
He plays with his genitals. & 50 & 2.2400 & .79693 \\
He cry's a lot and being nervous. & 50 & 2.2800 & .72955 \\
He speaks about himself in a bad manner. & 50 & 2.3200 & .76772 \\
He lies to his brothers. & 50 & 2.3800 & .75295 \\
He looks at himself as better than his colleagues. & 50 & 2.4000 & .72843 \\
He uses the filthy words. & 50 & 2.4000 & .69985 \\
He is stubborn and does not listen to the words. & 50 & 2.4600 & .67643 \\
He tends to destroy and damage the things. & 50 & 2.4800 & .61412 \\
People describe him as a shy person & 50 & 2.5200 & .70682 \\
Valid N (listwise) & & & \\
\hline
\end{tabular}

The results of the descriptive analysis also showed that " He steals from the house", was at a lowest level compared to the above ten items. It can be inferred that this item is the relative weaknesses of the mother, it exhibited very low level mean scores with (M =2.1200, S.D. $=.82413$ ). Thus, it can be concluded that this item of group one can still be unknown for the mothers. 
Table 5. Descriptive Statistics of the Group Five

\begin{tabular}{|l|r|r|r|}
\hline & & \multicolumn{2}{|c|}{} \\
\cline { 2 - 4 } & & Mean & Std. Deviation \\
\hline He suffers from some the health problems. & 50 & 2.2800 & .85809 \\
Many times he initiates doing things. & 50 & 2.3600 & .59796 \\
He love his family members. & 50 & 2.3800 & .72534 \\
He eats too much. & 50 & 2.4000 & .72843 \\
He harshly plays with the animals. & 50 & 2.4000 & .57143 \\
Sometimes he feels he is a failure. & 50 & 2.4200 & .70247 \\
He speaks about killing himself. & & & .73290 \\
He seems meek with people. & 50 & 2.4400 & .54248 \\
He looks a lot to the ceiling & 50 & 2.4600 & .73540 \\
Valid N (listwise) & & & \\
\hline
\end{tabular}

"He suffers from some the health problems", was at a lower level compared to the above ten items. It can be inferred that this item is the relative weaknesses at the mother, it exhibited very low level mean scores with $(\mathrm{M}=2.2800$, S.D. $=.85809)$. Thus, it can be concluded that this item of group one can still be unknown at the mothers.

On the other hand, to compare the mean score for five groups of the questioner we used one sample T-test. T-test tell us whether there is a statistically significant differences in the mean score if the Sig. (2-tailed) column equal or less than 0,05 which refers there is a significant differences in the mean score. However, Data from table (6) explore that the all the means scores below 3, which means that all the mothers haven't the sufficient knowledge about children abuse phenomena. 


\section{One-Sample Statistics}

\begin{tabular}{|l|r|r|r|c|}
\hline & $\mathrm{N}$ & Mean & Std. Deviation & $\begin{array}{c}\text { Std. Error } \\
\text { Mean }\end{array}$ \\
\hline MeanCB & 50 & 2.3222 & .42011 & .05941 \\
MeanCCB & 50 & 2.3782 & .34280 & .04848 \\
MeanCCCB & 50 & 2.3360 & .45165 & .06387 \\
MeanCBCB & 50 & 2.3600 & .45311 & .06408 \\
MeanCCBCCB & 50 & 2.4000 & .38651 & .05466 \\
MeanTotal & 50 & 2.3604 & .31064 & .04393 \\
\hline
\end{tabular}

One-Sample Test

\begin{tabular}{|c|c|c|c|c|c|c|}
\hline & \multicolumn{6}{|c|}{ Test Value $=3$} \\
\hline & \multirow[b]{2}{*}{$t$} & \multirow[b]{2}{*}{$\mathrm{df}$} & \multirow{2}{*}{$\begin{array}{c}\text { Sig. } \\
\text { (2-tailed) }\end{array}$} & \multirow{2}{*}{$\begin{array}{c}\text { Mean } \\
\text { Difference }\end{array}$} & \multicolumn{2}{|c|}{$\begin{array}{l}95 \% \text { Confidence } \\
\text { Interval of the } \\
\text { Difference }\end{array}$} \\
\hline & & & & & Lower & Upper \\
\hline MeanCB & -11.408 & $\overline{49}$ & .000 & -.67778 & -.7972 & -.5584 \\
\hline MeanCCB & -12.827 & 49 & .000 & -.62182 & -.7192 & -.5244 \\
\hline MeanCCCB & -10.396 & 49 & .000 & -.66400 & -.7924 & -.5356 \\
\hline MeanCBCB & -9.988 & 49 & .000 & -.64000 & -.7688 & -.5112 \\
\hline MeanCCBCCB & -10.977 & 49 & .000 & -.60000 & -.7098 & -.4902 \\
\hline MeanTotal & -14.559 & 49 & .000 & -.63960 & -.7279 & -.5513 \\
\hline
\end{tabular}

It is useful to do the comparing dimensional correlation with each dimension, all dimensions are Correlated significant at the 0.01 level (2-tailed) with each other and with the total features of child abuse, except CCB with CCBCCB with (623). However, It is noted that the highest degree of correlation was $\mathrm{CCCB}$, with the lowest correlation coefficient between CCBCCB. Regarding the correlation the dimensions together $\mathrm{CB}$ with $\mathrm{CCB}$ equal 0.680 , and the lowest correlation between $\mathrm{CCB}$ with $\mathrm{CCBCC}$, which means there is not statistically significant. 


\begin{tabular}{|c|c|c|c|c|c|c|c|}
\hline \multicolumn{8}{|c|}{ Correlations } \\
\hline & & MeanCB & MeanCCB & MeanCCCB & MeanCBCB & $\begin{array}{c}\text { Mean } \\
\text { CCBCCB }\end{array}$ & MeanTotal \\
\hline \multirow{3}{*}{ MeanCB } & Pearson Correlation & $\overline{1}$ & $.680^{\star \star}$ & $.475^{\star \star}$ & $.476^{\star *}$ & $.293^{*}$ & $.759^{*}$ \\
\hline & Sig. (2-tailed) & & .000 & .000 & .000 & .039 & .000 \\
\hline & $\mathrm{N}$ & 50 & 50 & 50 & 50 & 50 & 50 \\
\hline \multirow[t]{3}{*}{ MeanCCB } & Pearson Correlation & $.680^{* *}$ & 1 & $.460^{\star \star}$ & $.403^{* *}$ & .176 & $.703^{*}$ \\
\hline & Sig. (2-tailed) & .000 & & .001 & .004 & .220 & .000 \\
\hline & $\mathrm{N}$ & 50 & 50 & 50 & 50 & 50 & 50 \\
\hline \multirow[t]{3}{*}{ MeanCCCB } & Pearson Correlation & $.475^{\star *}$ & $.460^{* *}$ & 1 & $.745^{\star *}$ & $.372^{* *}$ & $.828^{*}$ \\
\hline & Sig. (2-tailed) & .000 & .001 & & .000 & .008 & .000 \\
\hline & $\mathrm{N}$ & 50 & 50 & 50 & 50 & 50 & 50 \\
\hline \multirow[t]{3}{*}{ MeanCBCB } & Pearson Correlation & $.476^{\star *}$ & $.403^{* *}$ & $.745^{\star \star}$ & 1 & $.522^{\star \star}$ & $.852^{\star *}$ \\
\hline & Sig. (2-tailed) & .000 & .004 & .000 & & .000 & .000 \\
\hline & $\mathrm{N}$ & 50 & 50 & 50 & 50 & 50 & 50 \\
\hline \multirow[t]{3}{*}{ MeanCCBCCB } & Pearson Correlation & $.293^{*}$ & .176 & $.372^{\star *}$ & $.522^{* *}$ & 1 & $.623^{\star}$ \\
\hline & Sig. (2-tailed) & .039 & .220 & .008 & .000 & & .000 \\
\hline & $\mathrm{N}$ & 50 & 50 & 50 & 50 & 50 & 50 \\
\hline \multirow[t]{3}{*}{ MeanTotal } & Pearson Correlation & $.759^{* *}$ & $.703^{* *}$ & $.828^{* *}$ & $.852^{* *}$ & $.623^{* *}$ & 1 \\
\hline & Sig. (2-tailed) & .000 & .000 & .000 & .000 & .000 & \\
\hline & $\mathrm{N}$ & 50 & 50 & 50 & 50 & 50 & 50 \\
\hline
\end{tabular}

${ }^{* \star}$. Correlation is significant at the 0.01 level (2-tailed).

*. Correlation is significant at the 0.05 level (2-tailed).

\section{Discussing the Results}

This current study has reached that the mothers do not have the sufficient knowledge about the concept children abuse, inside the house, since the responses to all of the dimensions were below the medium, and some of the fathers and mothers abuse their children thinking that this is one of disciplines to make them acquire the desired behavior, and preventing them from the abnormal behavior.

Child maltreatment is global illness phenomenon no one can ignore it, human society is suffering from the associations provide the help have listed it within the behavioral problems. From this point, parents, male and female educators and everyone are advised not to over treat the child under any excuse and follow the rational behavior in dealing with him to avoid our children the behavioral problems, violence only creates violence, and there are many aid means (other than punishment ) help the child acquire the appropriate behaviors.

It is possible to note that the abused child creates the negative feelings, and will be affected psychologically and becomes stubborn, generally characterized by anger, and over sensitive, which makes upbringing more difficult. From the other side, abusing the child makes him victim, his life and future will be affected by that. The child seems sad, fearful, and even seems lacks the power and capability, so, he cannot do anything; his feeling becomes deep to a degree that he cannot abut them to anybody.

\section{References}

Abualsondos, R. (2004). Role of the international institute for the women solidarity / Jordan in Providing the Aid to the Women and the Girls, and the Effect of that on Limiting Children 
Abuse. Work Paper Presented to the First Arabic Conference of the International Association for Preventing Children Abuse During the Period (25-2/2004).

Abujaber, M, Alaaldeen, J, Akroosh, L., \& Al-Farah, Y. (2008). Parents perceptions to children problems and abusing them in the Jordanian society, Jordanian Journal in Educational Science, 5(1).

Al-awartani,W. (2004). Teacher Maltreatment and its Relation to Academic Achievement, Self-Valuation of the Ninth Basic Grade Students in Amman, (Unpublished Master Thesis), University of Jordan, Amman, Jordan.

Albalbeesi , B. (1997). Size of Child Abuse Problem in the Jordanian Society, Working Paper Introduced to the Child abuse Seminar. Jordan river association, in cooperation with the united nation organization for children/UNICEF, Amman, Jordan.

Al-Haj, A. (1999). Family Violence Against the Child in the Jordanian society, (Unpublished Thesis Master), University of Jordan, Jordan.

Alqaisi, H. (2004). Effect of Abuse (Emotional and Physical), Ignorance in its Two Types, Emotional and Physical (on the Multiple Developmental Intelligence). (Unpublished Doctorate Dissertation), Faculty of Graduate Studies, University of Jordan.

Al-Qaisi, L. (2006). Child Abuse and its Relation to his Psychological Problem and to Parents Marriage Adjustment. (Unpublished Doctoral Thesis), University of Jordan, Amman, Jordan.

Al-Swaig, S. (2003). Children abuse and their Negligence: Field study in Al-Riyad city. Journal of Childhood and Development, 70(9), 3.

Altarawneh, F. (1999). Forms of Child's Parental Abuse and their Relation to his Psychological Stress and Some of his family's Demographic Characteristics, (Unpublished Master Thesis), Mu'ta University, AlKarak, Jordan.

Ilyas, T., Al-hadeedi, M., Jahshan, H., \& Ratroot, S. (2001). Risk Factor Leading to Abusing Segment of Abused Children in the Hashemite Kingdom of Jordan.

Khlaqi, H., C. (1990). Rationality between physical and sexual abuse and some of the demographic variables related to the abusing family, unpublished master thesis, university of Jordan, Jordan.

Raroot, A. (2001). Abuse Modes Against the Children by their Family Individuals and their Relation with Some Social and Economic Variables, (Unpublished Master Thesis), University of Jordan, Jordan.

Rbaihat, S. (1988). Size and Forms of Children Abuse in Jordan. Information and Studies Management, Directorate of General Security, Amman, Jordan. 